\title{
Гальваномагнитные свойства и термоэдс ультратонких пленок системы висмут-сурьма на подложке из слюды
}

\author{
(C) В.А Герега, А.В Суслов, В.А Комаров, В.М Грабов, Е.В Демидов, А.В Колобов \\ Российский государственный педагогический университет им. А.И. Герцена, \\ 191186 Санкт-Петербург, Россия \\ E-mail: gerega.vasilisa96@gmail.com
}

Поступила в Редакцию 19 сентября 2021 г.

В окончательной редакции 24 сентября 2021 г.

Принята к публикации 24 сентября 2021 г.

\begin{abstract}
Исследование электронных свойств ультратонких пленок чистого висмута и сплавов висмут-сурьма представляет интерес в связи с обнаруженным ростом проводимости при уменьшении толщины образцов. В работе представлены результаты экспериментального исследования структуры, электрических, гальваномагнитных и термоэлектрических свойств тонких пленок чистого висмута и $\mathrm{Bi}_{1-x} \mathrm{Sb}_{x}(x=0.05$ и 0.12$)$ на подложке из слюды в диапазоне толщин 10-30 нм. Обнаружено увеличение проводимости при уменьшении толщины образцов, которое может быть связано с наличием поверхностных топологически защищенных состояний. Показано, что на особенности проявления этого эффекта значительно влияет зонная структура сплавов. Характер температурных зависимостей коэффициента Зеебека ставит под сомнение тот факт, что поверхностные состояния положительно влияют на термоэлектрическую эффективность тонких пленок висмут-сурьма. Однако обнаружение положительной термоэдс в образцах $\mathrm{Bi}_{0.88} \mathrm{Sb}_{0.12}$ может стать важным фактором для поиска возможности создания $p$-ветви термоэлектрических преобразователей.
\end{abstract}

Ключевые слова: висмут, сурьма, тонкие пленки, поверхностные состояния, термоэдс.

DOI: $10.21883 /$ FTP.2022.01.51810.26

\section{1. Введение}

Кристаллы и низкоразмерные объекты на основе висмута и его сплавов с сурьмой давно вызывают теоретический и практический интерес, что связано с особенностями их кристаллической структуры и энергетического спектра носителей заряда, которые обусловливают уникальные электронные и термоэлектрические свойства [1-4]. К таким особенностям относятся, например, сильная анизотропия поверхностей Ферми, малые эффективные массы, большие значения длины свободного пробега и длины волн де Бройля носителей заряда, сильное спин-орбитальное взаимодействие. Указанные особенности обусловливают интерес к исследованию проявлений классических [5] и квантовых размерных эффектов на этом классе материалов [6]. Так, во многих работах были обнаружены осцилляции магнетосопротивления и коэффициента Холла в ультратонких пленках чистого висмута в зависимости от толщины, которые связывают с квантовым размерным эффектом [7-9]. Кроме того, в ультратонких пленках чистого висмута обнаружен переход температурной зависимости удельного сопротивления от полупроводникового типа к виду, характерному для металлов, при этом происходит значительный рост концентрации носителей заряда [10]. Однако по различным литературным данным граница перехода имеет разные значения $[11,12]$. Это может быть связано с различным типом подложки и, соответственно, различной величиной деформации пленки.

Интерес к исследованию сплавов висмута возрос после экспериментального подтверждения свойств топо- логического изолятора в объемных кристаллах $\mathrm{Bi}_{0.9} \mathrm{Sb}_{0.1}$ методом фотоэмиссионной спектроскопии с угловым разрешением (ARPES) [13]. В работах [14,15] показано, что зонная структура чистого висмута является тривиальной, при этом зонная структура сурьмы и ее тонких пленок имеет нетривиальную топологию. На основе этого полагается, что сплавы висмут-сурьма будут обладать нетривиальной топологической структурой, начиная с концентрации сурьмы $x>0.04$, которая соответствует инверсии зон. Однако в работе [16] показано, что в чистом висмуте поверхностные состояния соединяются с объемными состояниями валентной зоны и зоны проводимости, указывая на его нетривиальную топологическую структуру. Недавние исследования тонких пленок висмута с помощью ARPES и сканирующей электронной микроскопии показали, что в поверхностных состояниях чистого висмута проявляется эффект Рашбы, а топология зонной структуры висмута определенно имеет нетривиальный характер, условием возникновения которого является увеличение ширины запрещенной зоны в $L$-точке вследствие квантового размерного эффекта [17-19].

С помощью расчетов на основе теории функционала плотности было показано, что в массивном состоянии висмут действительно обладает тривиальной топологией зонной структуры, однако квантование по толщине или изменение постоянной кристаллической решетки вследствие плоскостной деформации до 10\% приводит к появлению нетривиальных состояний в зонной структуре [20]. В работе [20] влияние деформации на зонную 
структуру было рассмотрено в приближении массивного кристалла.

В современной литературе исследования ультратонких пленок системы висмут-сурьма представлены в меньшей степени. Температурные и толщинные зависимости электрических, гальваномагнитных и термоэлектрических свойств, представленные в литературе, часто имеют фрагментарный характер, что не позволяет провести комплексный анализ изменений зонной структуры пленок. Согласно работе [21], переход температурной зависимости удельного сопротивления от полупроводникового типа к металлическому наблюдается у тонких пленок чистого висмута, а также у пленок висмутсурьма 7 и 11 ат\% Sb толщиной < 17 нм. Важным этапом преодоления разрозненности представленных данных является комплексное исследование электрических, гальваномагнитных и термоэлектрических свойств пленок висмута и сплавов на его основе в достаточно широком диапазоне толщин и составов. Особый интерес представляют пленки чистого висмута и висмут-сурьма с содержанием сурьмы 7-22ат\% и близкие к ним составы для определения границ и условий образования нетривиальных топологических состояний.

Исследования тонких пленок висмута и сплавов висмут-сурьма вызывают значительный теоретический и практический интерес в связи с достаточно высокими значениями коэффициента Зеебека [22,23]. Кроме того, теоретически было показано, что квантовое ограничение может значительно улучшить термоэлектрическую добротность ультратонких пленок многих материалов [24]. Высокая подвижность поверхностных топологических состояний позволяет увеличить электропроводность материала, при этом его теплопроводность определяется объемными свойствами. Это позволило бы достичь повышения термоэлектрической добротности, которое требует сочетания высокой электропроводности и низкой теплопроводности. Таким образом, исследование влияния поверхностных состояний на термоэлектрические свойства представляет интерес, однако данные по таким исследованиям ультратонких пленок твердых растворов висмут-сурьма недостаточно полно представлены в современной литературе.

\section{2. Методика эксперимента}

Исследованные образцы были получены методом термического испарения в вакууме $\sim 10^{-5}$ Торр в диапазоне толщин 10-30 нм на подложке из слюды (мусковит). В качестве напыляемого вещества использовался висмут чистоты 99.999\%, а также полученные на его основе твердые растворы висмут-сурьма с 5 и 12 ат\% $\mathrm{Sb}$. Температура подложки при напылении составляла $393 \mathrm{~K}$, температура отжига - $473 \mathrm{~K}$, время отжига - 1 ч. Коэффициенты температурного расширения подложки и висмута различны, поэтому на свойствах пленки отражаются механические деформации - растяжение в плоскости образца в случае слюды при температурах ниже температуры формирования пленок [25]. Для проведения измерений явлений переноса носителей заряда в пленках на них наносились контактные площадки из манганина методом термического испарения в вакууме. Для измерения термоэлектрических свойств образцов на обратной стороне подложки аналогичным методом формировалась дополнительная пленочная структура.

Исследование структуры поверхности полученных пленок проводилось методом атомно-силовой микроскопии (ACM) в полуконтактном и контакном режимах. Для контроля толщины образцов и определения размеров кристаллитов пленок метод АСМ применялся в сочетании с методом избирательного химического травления, описанным в [26]. Время травления выбиралось в зависимости от толщины, рассчитанной по массе напыляемого вещества, и составляло 5-30 с. Точность измерения толщины по данной методике составляет 10\%.

Измерения всех исследованных транспортных свойств тонкопленочных образцов проводились на одном и том же образце в едином технологическом цикле при помощи специализированной установки. Установка устроена таким образом, что исследуемый образец с подведенными к нему контактами располагается внутри медного криостата. В объеме криостата создается вакуум, что увеличивает однородность и стабильность температуры и повышает точность измерений, исключая взаимодействие образца и подведенных к нему контактов с внешней средой. В криостате реализован метод крепления образца, обеспечивающий отсутствие жесткого механического контакта между системой пленка-подложка и телом криостата, что исключает деформацию пленки элементами криостата в процессе измерений. Установка позволяет проводить измерения при постоянном токе в постоянном магнитном поле до 0.7 Тл со стабилизацией температуры в точках в интервале $77-300 \mathrm{~K}$.

Транспортные свойства носителей заряда тонких пленок висмута и сплавов висмут-сурьма существенно зависят от механических деформаций. Поэтому методики измерения термоэдс, в которых используется жесткий контакт образца с градиентной пластиной с помощью теплопроводящей смазки, не могут быть использованы в данном случае, так как значительное различие КТР пластины и подложки приведет к искажению результатов изменений, особенно в низкотемпературной области вследствие деформирования образца. В связи с этим для измерения температурных зависимостей термоэдс применялся метод, описанный в работе [27], который исключает механический контакт образца с элементами криостата, а значит, и внесение в систему пленкаподложка дополнительных механических напряжений. Для этого на обратной стороне подложки относительно пленки формировалась дополнительная пленочная структура, состоящая из медного термометра сопротивления и пленочного нагревателя. При небольшой толщине слюдяной подложки (5-40 мкм) температуру 
термометра сопротивления и пленки в зоне контакта можно считать одинаковой.

\section{3. Экспериментальные результаты и обсуждение}

Результаты АСМ-исследования структуры поверхности полученных образцов свидетельствуют о том, что их кристаллографическая ориентация одинакова: тригональная ось перпендикулярна плоскости подложки. Средний размер кристаллитов пленок составляет 0.5-1 мкм, т.е. для всех составов размер кристаллитов превосходит толщину пленки на 2 порядка. Однако при добавлении сурьмы размер кристаллитов в среднем уменьшается. С другой стороны, для всех образцов характерно увеличение отношения размера кристаллитов к толщине пленки при уменьшении толщины образца.

На температурной зависимости удельного сопротивления пленок чистого висмута исследованных толщин на слюде можно выделить два интервала: 20-30 и 10-18 нм (рис. 1). На зависимостях первого интервала (20-30нм) удельное сопротивление растет при понижении температуры, во втором интервале толщин (10-18 нм) температурная зависимость удельного сопротивления имеет вид, характерный для металлов, т.е. убывает при понижении температуры. При этом для всех исследованных образцов удельное сопротивление при низких температурах оказывается даже ниже, чем в пленках большей толщины. Полученные результаты подтверждают аналогичные закономерности, полученные в пленках висмута на подложках из слюды в работах $[9,28,29]$.

По абсолютному значению удельное сопротивление образцов $\mathrm{Bi}_{0.95} \mathrm{Sb}_{0.05}$ больше, чем у образцов из чистого висмута соответствующей толщины, что связано

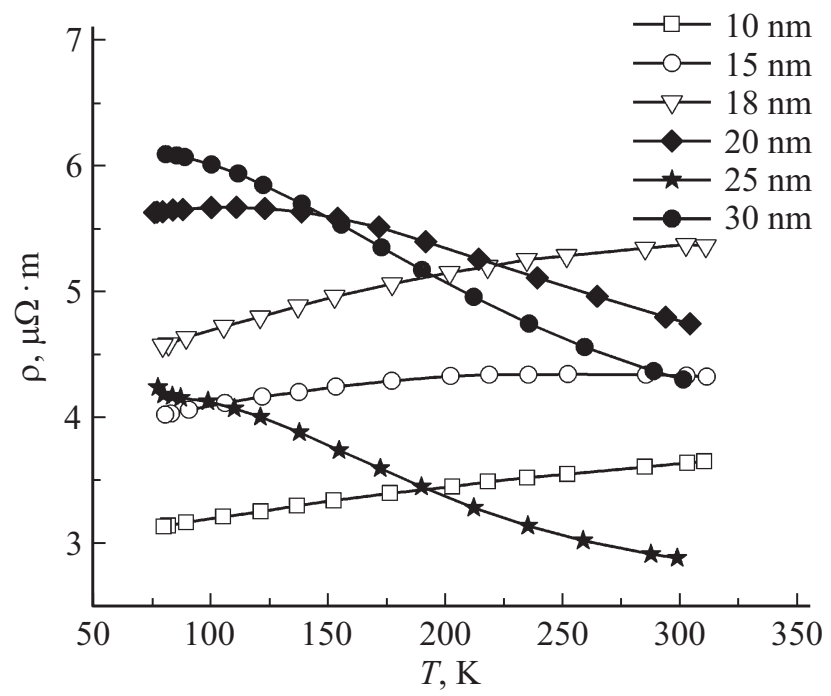

Рис. 1. Температурная зависимость удельного сопротивления пленок чистого Bi.

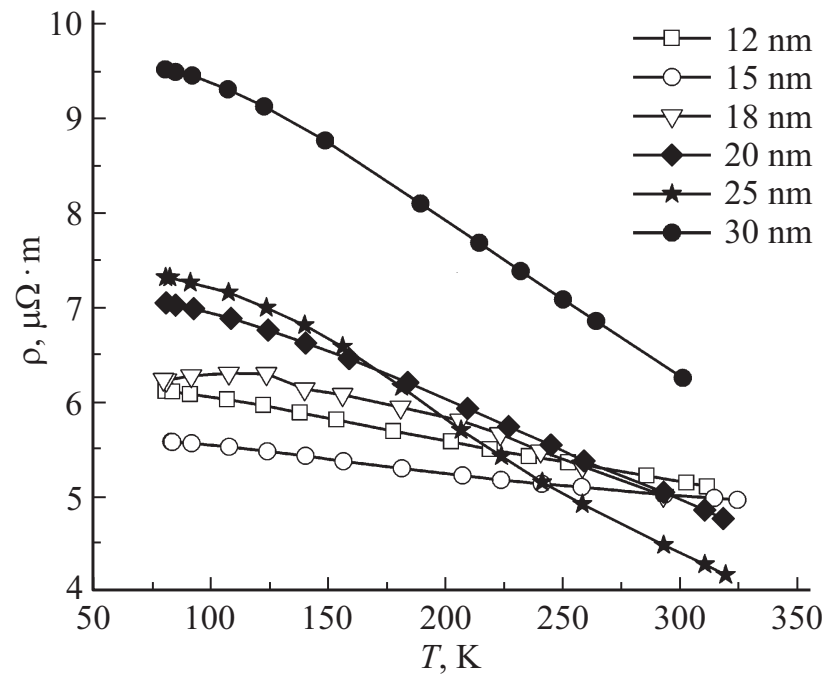

Рис. 2. Температурная зависимость удельного сопротивления пленок $\mathrm{Bi}_{0.95} \mathrm{Sb}_{0.05}$.

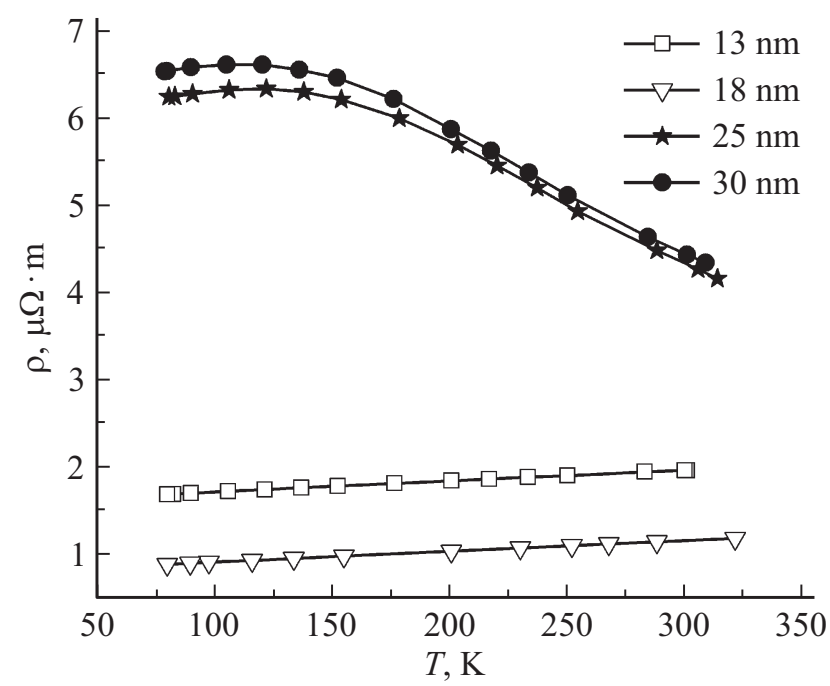

Рис. 3. Температурная зависимость удельного сопротивления пленок $\mathrm{Bi}_{0.88} \mathrm{Sb}_{0.12}$.

с меньшими размерами кристаллитов и уменьшением перекрытия зон в $L$ - и $T$-точках относительно чистого висмута. Однако при уменьшении толщины образцов удельное сопротивление уменьшается по абсолютной величине. При этом переход температурной зависимости к металлическому виду не наблюдается (рис. 2).

На температурных зависимостях удельного сопротивления образцов $\mathrm{Bi}_{0.88} \mathrm{Sb}_{0.12}$ наблюдается ярко выраженный переход к металлическому виду (рис. 3). По абсолютному значению удельное сопротивление образцов наименьшей толщины оказывается меньше, чем у пленок чистого висмута аналогичной толщины, при том что массивные кристаллы этого состава являются полупроводниками и не имеют перекрытия зон, как в чистом висмуте. Для всех образцов характерно уменьшение удельного сопротивления при уменьшении толщины. 
В пленках чистого висмута в интервале толщин 20-30 нм магнетосопротивление заметно изменяется в интервале температур 77-300 К, в то время как в пленках в интервале толщин 10-18 нм магнетосопротивление мало и слабо зависит от температуры. Относительное магнетосопротивление пленок $\mathrm{Bi}_{0.95} \mathrm{Sb}_{0.05}$ и $\mathrm{Bi}_{0.88} \mathrm{Sb}_{0.12}$ близко к нулю и не зависит от температуры во всем исследованном интервале толщин. Малое или не наблюдающееся магнетосопротивление говорит о том, что подвижность носителей электрического заряда уменьшается при уменьшении толщины пленок. Сочетание уменьшения удельного сопротивления и магнетосопротивления при уменьшении толщины качественно свидетельствует о росте концентрации носителей заряда с уменьшением толщины пленки. Это характерно для всех исследованных образцов. В связи с этим можно ожидать наибольший рост концентрации для состава $\mathrm{Bi}_{0.88} \mathrm{Sb}_{0.12}$.

Эффекты Холла и Зеебека имеют разностный характер, т. е. сильно зависят от соотношения вкладов электронной и дырочной компонент. В тригональной плоскости кристаллов чистого висмута и сплавов висмутсурьма компонента коэффициента Холла отрицательна и достаточно мала, что делает ее чувствительной к различным факторам, поэтому в тонких пленках наблюдается широкий разброс как по ее абсолютному значению, так и по знаку. В висмуте вследствие анизотропии наименьшая подвижность дырок наблюдается вдоль тригональной оси, а электронов — в перпендикулярном ей направлении, поэтому при интерпретации результатов измерений необходимо учитывать различное ограничение подвижностей носителей зарядов на поверхности и границах кристаллитов [30]. Однако изменение соотношения вкладов может быть обусловлено и другими причинами, в том числе влиянием поверхностных состояний и деформаций.

На рис. 4 приведены температурные зависимости коэффициента Холла и термоэдс (см. вставку) чистого висмута. Коэффициент Холла всех пленок положителен, что наблюдается и в поликристаллических пленках на слюдяной подложке толщиной порядка микрометра, размеры блоков которых превосходят толщину самой пленки. В таких пленках ограничение электронной составляющей толщиной проявляется существеннее, чем ограничение дырочной составляющей размерами кристаллитов [30]. При уменьшении толщины образцов значение коэффициента Холла в среднем уменьшается. Коэффициент Зеебека исследованных пленок чистого висмута отрицателен, и он уменьшается по абсолютному значению при понижении температуры (см. вставку на рис. 4). В работе [31] показано, что при толщинах $>30$ нм происходит уменьшение коэффициента Зеебека по абсолютному значению относительно образцов толщинами 0.1-1 мкм.

На всех зависимостях коэффициента Холла пленок $\mathrm{Bi}_{0.95} \mathrm{Sb}_{0.05}$ также наблюдается максимум, который смещается в область более высоких температур с уменыше-

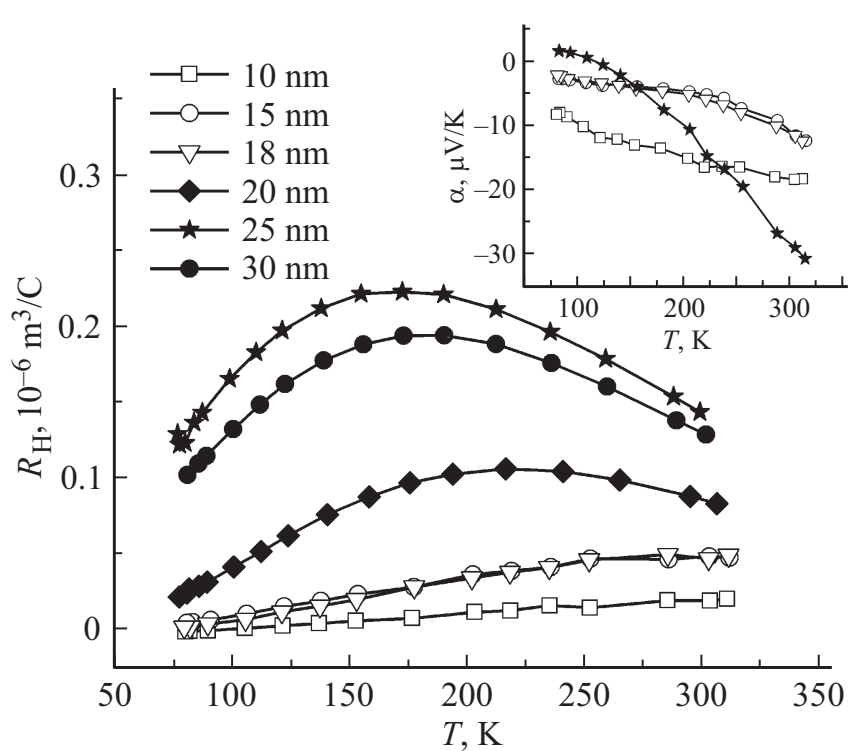

Рис. 4. Температурная зависимость коэффициента Холла пленок чистого Вi. На вставке - температурная зависимость термоэдс пленок чистого Bi.

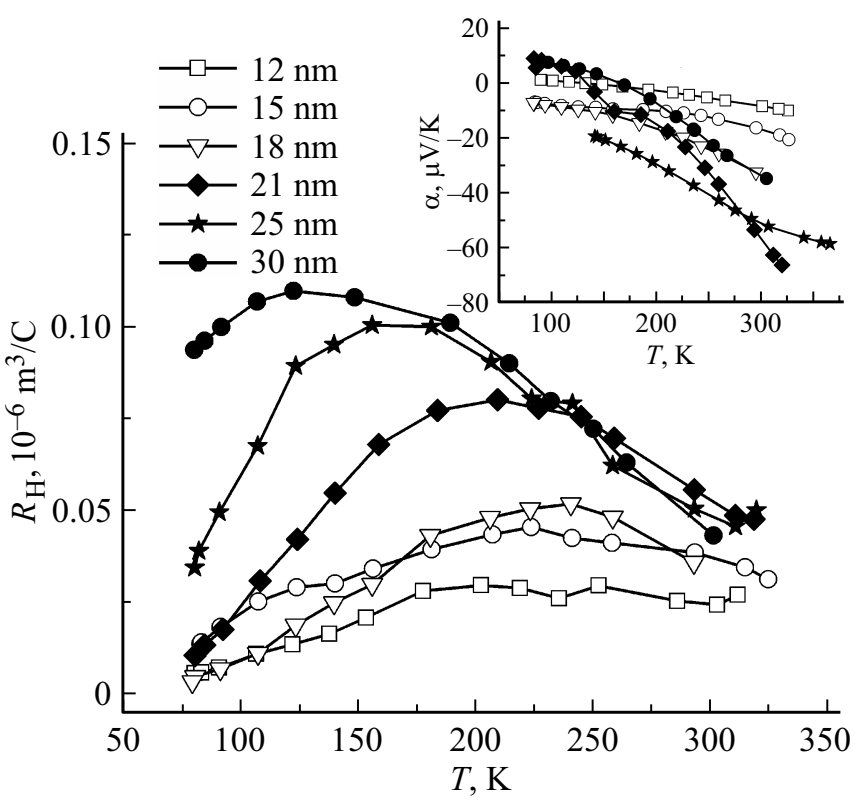

Рис. 5. Температурная зависимость коэффициента Холла пленок $\mathrm{Bi}_{0.95} \mathrm{Sb}_{0.05}$. На вставке - температурная зависимость термоэдс пленок $\mathrm{Bi}_{0.95} \mathrm{Sb}_{0.05}$.

нием толщины пленки (рис. 5). Во всех исследованных образцах коэффициент Холла положителен, в то время как в монокристаллах и пленках большей толщины на подложках из слюды, где размер кристаллитов превосходит толщину пленки, он имеет отрицательный знак. Для более толстых пленок $(\sim 0.5-1$ мкм $)$ этого состава коэффициент Зеебека растет при уменьшении температуры. Однако для исследованных ультратонких пленок $\mathrm{Bi}_{0.95} \mathrm{Sb}_{0.05}$ его температурная зависимость ана- 


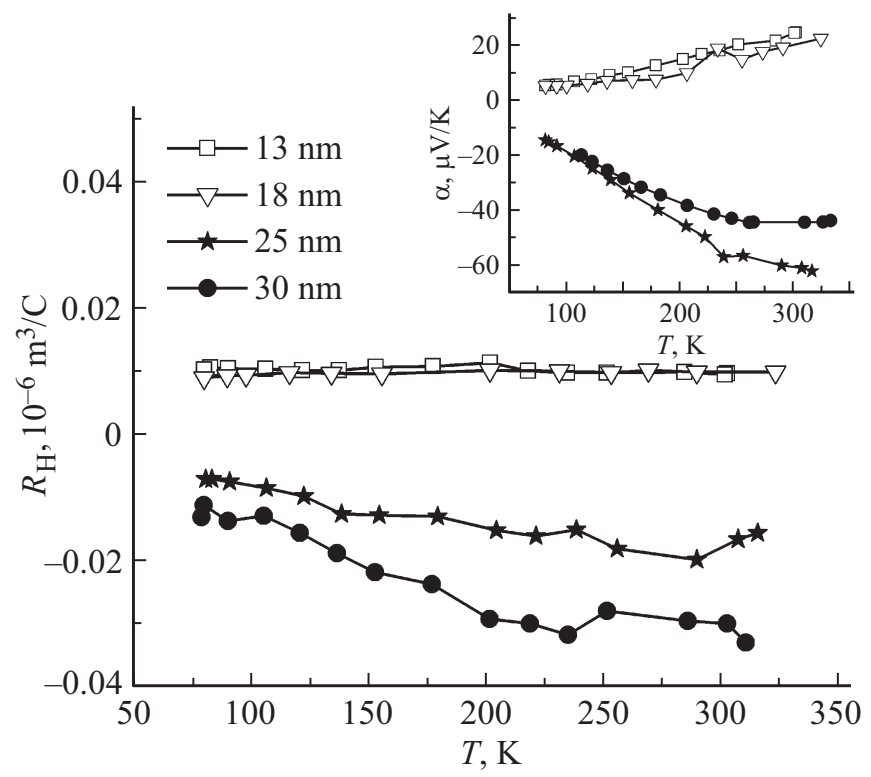

Рис. 6. Температурная зависимость коэффициента Холла пленок $\mathrm{Bi}_{0.88} \mathrm{Sb}_{0.12}$. На вставке - температурная зависимость термоэдс пленок $\mathrm{Bi}_{0.88} \mathrm{Sb}_{0.12}$.

логична той, что наблюдается на образцах чистого висмута этого диапазона толщин, т.е. коэффициент Зеебека отрицателен и уменьшается по абсолютной величине при уменьшении температуры (см. вставку на рис. 5).

Для кристаллов и более толстых пленок $\mathrm{Bi}_{0.88} \mathrm{Sb}_{0.12}$ так же, как и в случае $\mathrm{Bi}_{0.95} \mathrm{Sb}_{0.05}$, характерно отрицательное значение коэффициента Холла, что наблюдается на исследованных пленках толщиной 25-30нм. Однако при уменьшении толщины (< 18 нм) происходит изменение знака коэффициента Холла с отрицательного на положительный, при этом его значение весьма мало для всех исследованных образцов (рис. 6). Кроме того, на температурных зависимостях термоэдс этого состава наблюдается изменение знака на противоположный при толщинах, соответствующих изменению знака коэффициента Холла (см. вставку на рис. 6). Зависимость так же, как и для предыдущих образцов, убывает при уменьшении температуры, что не характерно для более толстых пленок на слюде.

Обнаружение положительного значения термоэдс в тонких пленках $\mathrm{Bi}_{0.88} \mathrm{Sb}_{0.12}$ представляет интерес для создания $p$-ветви термоэлектрических преобразователей энергии в области низких температур. При увеличении концентрации сурьмы в системе висмут-сурьма происходит изменение зонной структуры, при котором актуализируется экстремум тяжелых дырок в $H$-точке. Поэтому изменение знака термоэдс в $\mathrm{Bi}_{0.88} \mathrm{Sb}_{0.12}$, в случае ультратонких пленок может быть обусловлено не только существенным ограничением подвижности электронов, но и проявлением вклада дырок в $H$-точке зоны Бриллюэна.

\section{4. Заключение}

В работе исследованы температурные зависимости удельного сопротивления, магнетосопротивления, коэффициента Холла и термоэдс пленок толщиной 10-30 нм чистого висмута и сплавов $\mathrm{Bi}_{0.95} \mathrm{Sb}_{0.05}$ и $\mathrm{Bi}_{0.88} \mathrm{Sb}_{0.12}$. Для всех исследованных образцов характерно уменьшение удельного сопротивления при уменьшении толщины, что в сочетании с уменьшением подвижности носителей заряда, о которой свидетельствует малое магнетосопротивление, качественно свидетельствует о росте концентрации носителей заряда. Как было установлено ранее, для пленок чистого висмута при уменьшении толщины наблюдается изменение вида температурной зависимости удельного сопротивления от полупроводникового типа к металлическому. Аналогичное изменение вида зависимости нами было обнаружено для пленок сплава $\mathrm{Bi}_{0.88} \mathrm{Sb}_{0.12}$ толщиной $<18$ нм, при этом для $\mathrm{Bi}_{0.95} \mathrm{Sb}_{0.05}$ смена вида температурной зависимости удельного сопротивления не наблюдалась. Металлический вид температурной зависимости удельного сопротивления сплава $\mathrm{Bi}_{0.88} \mathrm{Sb}_{0.12}$, монокристалл которого является узкозонным полупроводником, может свидетельствовать о вкладе в проводимость топологически защищенных поверхностных состояний.

Кроме того, уменьшение коэффициента Зеебека по абсолютному значению, характерное для всех исследованных образцов, и изменение знака с положительного на отрицательный при повышении температуры образцов $\mathrm{Bi}_{0.88} \mathrm{Sb}_{0.12}$ толщиной $<18$ нм ставят под сомнение то, что вклад топологически защищенных поверхностных состояний приводит к увеличению термоэлектрической эффективности материалов на основе ультратонких пленок висмут-сурьма. Несмотря на это, обнаруженная положительная термоэдс в тонких пленах $\mathrm{Bi}_{0.88} \mathrm{Sb}_{0.12}$ может стать важным фактором для поиска возможности создания $p$-ветви термоэлектрических преобразователей энергии в области низких температур.

\section{Финансирование работы}

Работа выполнена в рамках государственного задания при финансовой поддержке Министерства просвещения России (проект № FSZN-2020-0026).

\section{Конфликт интересов}

Авторы заявляют, что у них нет конфликта интересов.

\section{Список литературы}

[1] B. Lenoir, M. Cassart, J.-P. Michenaud, H. Scherrer, S. Scherrer. J. Phys. Chem. Solids, 57 (89), 89 (1996).

[2] H.Y. Lu, H.J. Liu, L. Pan, Y.W. Wen, X.J. Tan, J. Shi, X.F. Tang. J. Phys. Chem. C, 114, 21234 (2010).

[3] S. Singh, I. Valencia-Jaime, O. Pavlic, A.H. Romero. Phys. Rev. B, 97, 054108 (2018). 
[4] G.E. Smith, R. Wolfe. J. App. Phys., 33 (3), 841 (1962).

[5] В.М. Грабов, Е.В. Демидов, В.А. Комаров, М.М. Климантов. Изв. РГПУ им. А.И. Герцена, 122, 22 (2010).

[6] T. Hirahara, T. Shirai, T. Hajiri, M. Matsunami, K. Tanaka, S. Kimura, S. Hasegawa, K. Kobayashi. Phys. Rev. Lett., 115 (10), 106803 (2015).

[7] H. Asahi, T. Humoto, A. Kawazu. Phys. Rev. B, 9 (8), 3347 (1974).

[8] V.P. Duggal, R. Rup. J. App. Phys., 40 (2), 492 (1969).

[9] Е.В. Демидов, В.М. Грабов, В.А. Комаров, А.Н. Крушельницкий, А.В. Суслов, М.В. Суслов. ФТП, 53 (6), 736 (2019).

[10] V. Gerega, E. Demidov, V. Grabov, V. Komarov, A. Suslov. AIP Conf. Proceedings, 2308, 050007 (2020).

[11] E.I. Rogacheva, S.G. Lyubchenko, M.S. Dresselhaus. Thin Sol. Films, 516 (10), 3411 (2008).

[12] N. Wang, Y.-X. Dai, T.-L. Wang, H.-Z. Yang, Y. Qia. IUCrJ, 7, 49 (2020).

[13] D. Hsieh, D. Qian, L. Wray, Y. Xia, Y.S. Hor, R.J. Cava, M.Z. Hasan. Nature, 452, 970 (2008).

[14] L. Fu, C.L. Kane. Phys. Rev. B, 76, 045302 (2007).

[15] J.C.Y. Teo, L. Fu, C.L. Kane. Phys. Rev. B, 78, 045426 (2008).

[16] Y. Ohtsubo, L. Perfetti, M.O. Goerbig, P.L. Fevre, F. Bertran, A. Taleb-Ibrahimi. New J. Phys., 15, 033041 (2013).

[17] A. Takayama, T. Sato, S. Souma, T. Oguchi, T. Takahashi. Phys. Rev. Lett., 114, 066402 (2015).

[18] T. Hirahara, N. Fukui, T. Shirasawa, M. Yamada, M. Aitani, H. Miyazaki, M. Matsunami, S. Kimura, T. Takahashi, S. Hasegawa, K. Kobayashi. Phys. Rev. Lett., 109, 227401 (2012).

[19] S. Ito, B. Feng, M. Arita, A. Takayama, R.-Y. Liu, T. Someya, W.-C. Chen, T. Iimori, H. Namatame, M. Taniguchi, C.M. Cheng, S.-J. Tang, F. Komori, K. Kobayashi, T.-C. Chiang, I. Matsuda. Phys. Rev. Lett., 117, 236402 (2016).

[20] T.R. Chang, Q. Lu, X. Wang, H. Lin, T. Miller, T.-C. Chiang, G. Bian. Crystals, 9, 510 (2019).

[21] Y. Ueda, N.H.D. Khang, K. Yao, P.N. Hai. App. Phys. Lett., 110, 062401 (2017).

[22] G.E. Smith, R. Wolfe. J. Appl. Phys., 33 (3), 841 (1962).

[23] D.V. Damodara, N. Soundararajan. Phys. Rev. B, 35 (12), 5990 (1987).

[24] T.T.T. Nguyen, L.T. Dang, G.H. Bach, T.H. Dang, K.T. Nguyen, H.T. Pham, T.T. Nguyen, T.V. Nguyen, T.T. Nguyen, H.Q. Nguyen. Mater. Sci., 117 (8), 083104 (2020).

[25] Н.С. Каблукова, Е.В. Демидов, В.А. Комаров, Е.Е. Христич. Изв. РГПУ им. А.И. Герцена, 153, 13 (2012).

[26] Е.В. Демидов, В.А. Комаров, А.Н. Крушельницкий, А.В. Суслов. ФТП, 51 (7), 877 (2017).

[27] E.V. Demidov, V.M. Grabov, V.A. Komarov, A.V. Suslov, M.V. Suslov. J. Phys.: Conf. Ser., 857, 012006 (2017).

[28] A.N. Krushelnitckii, V.M. Grabov, V.A. Komarov, E.V. Demidov, N.S. Kablukova. Университет. науч. журн., 27, 56 (2017).

[29] А.Н. Крушельницкий, Е.В. Демидов, В.А. Комаров, В.М. Грабов, Н.С. Каблукова. Физика диэлектриков, 207 (2017).

[30] А.В. Суслов, В.М. Грабов, В.А. Комаров, Е.В. Демидов, С.В. Сенкевич, М.В. Суслов. ФТП, 53 (5), 616 (2019).

[31] В.А. Герега, М.В. Суслов, А.В. Суслов, В.М. Грабов, Е.В. Демидов, В.А. Комаров. Поверхность, 5, 55 (2021).

\section{Galvanomagnetic properties and thermoelectric power of ultrathin films of the bismuth-antimony system on a mica substrate}

\author{
V.A. Gerega, A.V. Suslov, V.A. Komarov, V.M. Grabov, \\ E.V. Demidov, A.V. Kolobov
}

Herzen State Pedagogical University, 191186 St. Petersburg, Russia

Abstract The study of the electronic properties of ultrathin films of pure bismuth and bismuth-antimony alloys is of interest, since an increase in conductivity with decreasing sample thickness was found. This paper presents the results of an experimental study of the structure, electrical, galvanomagnetic and thermoelectric properties of pure bismuth and $\mathrm{Bi}_{1-x} \mathrm{Sb}_{x}$ thin films $(x=0.05$ and 0.12 ) on a mica substrate in the thickness range of $10-30 \mathrm{~nm}$. An increase in the conductivity with a decrease in the thickness of the samples was found. It may be due to the presence of topologically protected surface states. It is shown that the features of the manifestation of this effect are significantly influenced by the alloys band structure. The form of the temperature dependences of the Seebeck coefficient casts doubt on the fact that surface states have a positive effect on the thermoelectric efficiency of thin bismuth-antimony films. However, the detection of a positive thermoelectric power in $\mathrm{Bi}_{0.88} \mathrm{Sb}_{0.12}$ samples can become an important factor for searching for the possibility of creating a $p$-branch of thermoelectric converters. 